\title{
Serosurvey and Molecular Detection of Toxoplasma gondii in Dogs in Rural Areas of Kazeroun District, Fars Province, Southern Iran
}

\author{
Zahra Rezaei $\left(\mathbb{D},{ }^{1}\right.$ Ali Zeighami, ${ }^{2}$ Reza Shahriarirad $\left(\mathbb{D},{ }^{2}\right.$ Amirhossein Erfani, ${ }^{2}$ \\ Mohammad Rastegarian, ${ }^{2}$ Nasir Arefkhah, ${ }^{3}$ Bahman Pourabbas, ${ }^{1}$ Fariba Ghorbani, ${ }^{4}$ \\ and Bahador Sarkari $\mathbb{i D}^{4,5}$ \\ ${ }^{1}$ Professor Alborzi Clinical Microbiology Research Center, Shiraz University of Medical Sciences, Shiraz, Iran \\ ${ }^{2}$ Student Research Committee, School of Medicine, Shiraz University of Medical Sciences, Shiraz, Iran \\ ${ }^{3}$ Cellular and Molecular Research Center, Yasuj University of Medical Sciences, Yasuj, Iran \\ ${ }^{4}$ Department of Parasitology and Mycology, School of Medicine, Shiraz University of Medical Sciences, Shiraz, Iran \\ ${ }^{5}$ Basic Sciences in Infectious Diseases Research Center, Shiraz University of Medical Sciences, Shiraz, Iran
}

Correspondence should be addressed to Bahador Sarkari; sarkarib@sums.ac.ir

Received 19 September 2021; Revised 2 December 2021; Accepted 6 December 2021; Published 15 December 2021

Academic Editor: José F. Silveira

Copyright (c) 2021 Zahra Rezaei et al. This is an open access article distributed under the Creative Commons Attribution License, which permits unrestricted use, distribution, and reproduction in any medium, provided the original work is properly cited.

\begin{abstract}
Background. Toxoplasma gondii is an intracellular protozoan parasite responsible for systemic disease in a wide range of warmblooded animals. The current study is aimed at evaluating the prevalence of Toxoplasma infection in dogs, using serological and molecular methods in rural areas in Kazeroun Township, Fars province, southern Iran. Methods. Blood samples were obtained from 60 clinically healthy dogs with an age range of 1 to 7 years in three rural areas of Fars province, southern Iran. Sera and buffy coats were used to assess the T. gondii infection using both modified agglutination test (MAT) and real-time PCR. Results. Antibodies against T. gondii were detected in 5 out of 60 (8.3\%) dogs by the MAT method, and T. gondii DNA was detected in 17 out of $60(28.3 \%)$ studied animals. There was no significant association between sex and seropositivity to Toxoplasma $(p>0.05)$. Fair agreement $(k a p p a=0.27)$ was seen between molecular and serological findings where three dogs with positive serological results had a positive molecular test. Conclusion. Findings of the present study show a relatively high prevalence of T. gondii infection in dogs in rural areas in Fars province, southern Iran. Finding the parasite genotype in dogs deserves further study.
\end{abstract}

\section{Introduction}

Toxoplasmosis is one of the most common zoonotic parasitic infections which has a high prevalence in human communities $[1,2]$. Infection mainly occurs through the consumption of water, food, or soil contaminated with oocytes excreted in cat feces. In addition, the infection can occur by using raw or undercooked meat, containing tissue cysts [2]. It is estimated that $30-50 \%$ of the world's population is infected with $T$. gondii, and more than one-third of infected individuals remained asymptomatic $[3,4]$.
The greatest concern of $T$. gondii infection is in pregnant women who get the infection for the first time since it can be transmitted to the fetus and causes abortion or fetal abnormalities such as ocular or neurological disorders [4]. Toxoplasmosis may also be fatal in immunocompromised individuals because of cerebral toxoplasmosis [5].

Although dogs do not excrete T. gondii oocysts in their feces and are not also consumed for foods in most countries, they can serve as a mechanical transmitter [2,6]. Since dogs are accustomed to rolling in cat feces, they can transmit the infection to humans via their fur $[6,7]$. 
Previous studies have shown that the prevalence of Toxoplasma infection among dogs varies in different regions of the world and even within the same country. It has been reported that the prevalence of Toxoplasma infection among dogs is 16 to $58 \%$ in America [8, 9], 21 to $68 \%$ in Asia [10, 11], 23 to $37 \%$ in Europe [12, 13], 19 to $25 \%$ in Africa [14, $15]$, and 10 to $31 \%$ in Oceania $[16,17]$. Nothing is known about the prevalence of toxoplasmosis in dogs from the rural area of Fars province. Hence, the current study is aimed at evaluating the prevalence of Toxoplasma infection in dogs using serological and molecular methods in this region.

\section{Materials and Methods}

2.1. Study Area and Sample Collection. Blood samples were obtained from 60 clinically healthy dogs with an age range of 1 to 7 years in three villages: Sarmashhad, Tole-e Saman, and Hosseinabad in Kazeroun County, Fars province, southern Iran. Ten $\mathrm{mL}$ of blood samples were collected by venipuncture of the cephalic vein from restrained dogs in tubes containing K3-EDTA. Plasma and buffy coats were separated and frozen at $-20^{\circ} \mathrm{C}$ for further serological and molecular tests. The study was approved by the Ethical Committee of Shiraz University of Medical Sciences (Ref. No. IR.SUMS.MED.REC.1398.174).

2.2. Modified Agglutination Test (MAT). Sera were tested for the presence of IgG against $T$. gondii, using the inhouse modified agglutination test (MAT) according to the method described by Desmonts and Remington [18]. Formalin-fixed tachyzoites of Toxoplasma were used as antigens. Serum samples were pretreated with $2 \mathrm{ME}$ for IgM elimination and diluted two-fold $(1: 20$ to $1: 160)$ in PBS buffer. Antibody titers of $\geq 1: 20$ were considered positive.

2.3. Detection of T. gondii by the Molecular Method. Buffy coats were digested in lysis buffer, containing $0.5 \%$ Tween 20, $0.5 \%$ Nonidet P-40, $10 \mathrm{mM} \mathrm{NaOH}, 10 \mathrm{mM}$ Tris ( $\mathrm{pH} 7.2$ ), and $320 \mathrm{mg}$ proteinase $\mathrm{K}$ and placed at $56^{\circ} \mathrm{C}$ for 24 hours and then boiled for 10 minutes. Then, DNA was extracted using the simplified phenol-chloroform extraction method using lysate followed by ethanol precipitation and resuspension in $50 \mu \mathrm{l}$ of TE (Tris-EDTA) buffer. The realtime PCR was performed using forward and reverse primers targeting a 35-copy number of B1 gene which amplifies a $130 \mathrm{bp}$ region of $T$. gondii [19]. Real-time PCR was performed, using a mixture containing $50 \mathrm{ng}$ of template DNA, 2x SYBR Green PCR Master Mix (Applied Biosystems, US), and $0.5 \mu \mathrm{M}$ of each primer in a final volume of $20 \mu \mathrm{l}$. The reaction was carried out using the StepOnePlus real-time PCR instrument (Applied Biosystems, US) as follows: 10 min hot start at $95^{\circ} \mathrm{C}, 35$ cycles at $95^{\circ} \mathrm{C}$ for $10 \mathrm{~s}, 68^{\circ} \mathrm{C}$ for $30 \mathrm{~s}$, and $72^{\circ} \mathrm{C}$ for $30 \mathrm{~s}$. A melting curve analysis was carried out after the completion of the amplification. Negative control (no template) and positive control (DNA isolated from the Toxoplasma tachyzoites) were included in the assay.

2.4. Statistical Analysis. Results of the molecular and serological tests, as well as the data related to age, sex, and sampling region, were statistically analyzed, using SPSS software (version 20, IBM Inc., USA) to determine any association between the variables.

\section{Results}

Samples were collected from 60 dogs, of which 23 (38.3\%) were from SarMashhad, 13 (21.7\%) were from Hosseinabad, and $24(40 \%)$ from Tole-e Saman village. Of the 60 studied dogs, 35 (58.3\%) were male and 25 (41.7\%) were female. The age range of the dogs was 1 to 7 years with the highest frequency of 2 years old with 13 cases (38.2\%), followed by 3 years with $9(26.5 \%)$ cases. Overall, the prevalence of Toxoplasma infection, using both serological and molecular methods, in the studied dogs was $31.67 \%$.

Antibodies to T. gondii were detected in $5(8.3 \%)$ out of 60 dogs by MAT. T. gondii DNA was detected in 17 (28.3\%) out of 60 dogs, of which 6 were from SarMashhad, 4 from Hosseinabad, and 7 from Tole-e Saman. Of the 17 dogs whose molecular test was positive, 9 were female, and 8 were male. Fair agreement $(k a p p a=0.27)$ was seen between molecular and serological findings where three dogs with positive serological results had a positive molecular test too. Table 1 shows the characteristics of evaluated dogs and relative prevalence of Toxoplasma infection.

\section{Discussion}

The overall frequency of Toxoplasma infection among stray dogs in rural areas of Kazeroun district in Fars province in southern Iran was found to be $31.7 \%$. Previous studies have shown different seroprevalences of Toxoplasma infection among dogs in a different region of Iran: $46.67 \%$ in Ahwaz [20], $10.7 \%$ and $35 \%$ in Hamedan [21, 22], and $22.47 \%$ in Tehran [23]. This difference in seroprevalence is due to differences in the population of dogs studied and kind of the serological tests used for the study, cutoff points, and various environmental and geographical conditions of the study area. Prevalence has been higher in studies that have used the ELISA system [20-23]. It has been documented that the ELISA is more sensitive than MAT for the detection of anti-Toxoplasma antibodies $[24,25]$. The seroprevalence obtained in the current study (8.3\%) was closed to the study performed by Gharekhani et al., with the same serological method and the population of the studied dogs [22]. However, the study area of Gharekhani et al. was different from the one in the current study. There is no information about the food consumed by dogs and also the prevalence of the infection in cats in this region. Also, there is no serosurvey of Toxoplasma infection in pregnant women in this region.

In a study by Arefkhah et al., the prevalence of Toxoplasma infection in children in the Sarmashad region, where the recent study has been conducted, was investigated. The findings of the study showed a $3.8 \%$ prevalence of Toxoplasma in this particular group of people in the community [26].

In the current study, the prevalence of the Toxoplasma infection was higher using the PCR method. There were twelve dogs with a positive result of PCR but negative MAT. The difference between the PCR and serological 
TABLE 1: Characteristics of evaluated dogs and relative prevalence of Toxoplasma infection, using serological and molecular methods, in rural areas in Fars province, southern Iran.

\begin{tabular}{|c|c|c|c|c|c|c|c|}
\hline & \multirow{2}{*}{ Frequency (no.) } & \multirow{2}{*}{ Percentage (\%) } & \multicolumn{2}{|c|}{$\begin{array}{l}\text { Positive for anti-Toxoplasma } \\
\text { antibodies }\end{array}$} & \multicolumn{2}{|c|}{ Positive for Toxoplasma DNA } & \multirow{2}{*}{$p$ value } \\
\hline & & & Frequency (no.) & Percent (\%) & Frequency (no.) & Percent (\%) & \\
\hline \multicolumn{8}{|l|}{$\overline{\text { Sex }}$} \\
\hline Male & 35 & 58.3 & 2 & 5.7 & 10 & 27.1 & 0.34 \\
\hline Female & 25 & 41.7 & 3 & 12 & 7 & 28 & \\
\hline \multicolumn{8}{|l|}{ Age (year) } \\
\hline $0-2$ & 16 & 26.6 & 2 & 12.5 & 8 & 50 & \multirow{4}{*}{0.06} \\
\hline $3-4$ & 26 & 43.4 & 2 & 5.6 & 6 & 23.1 & \\
\hline $5-6$ & 13 & 21.7 & 1 & 7.6 & 2 & 15.4 & \\
\hline$>6$ & 5 & 8.3 & 0 & 0 & 1 & 20 & \\
\hline \multicolumn{8}{|l|}{ Place } \\
\hline SarMashhad & 23 & 38.3 & 1 & 4.3 & 8 & 34.8 & \multirow{3}{*}{0.09} \\
\hline Hosseinabad & 13 & 21.7 & 3 & 23.1 & 4 & 30.8 & \\
\hline Tolesaman & 24 & 40.0 & 1 & 4.2 & 5 & 28.3 & \\
\hline
\end{tabular}

results in the current study might be attributed to the cut off point titer in MAT, removal of IgM in MAT procedures, immune status and age of the dogs, or the T. gondii strain [27]. As shown in previous studies, positive PCR results are mostly associated with acute infection, when the parasite is in the blood, while stimulation of the immune system and antibody production occurs after encystations of the parasite in the tissues [28].

In previous studies conducted by the researchers of the present study, same samples taken from the dogs examined in this study have been evaluated for Neospora and Leishmania infections $[29,30]$. Comparison of the findings of the present study with previous studies shows that only one case of dogs infected with Toxoplasma was also positive for Neospora infection. The results were similar for Leishmania, and only a small percentage (3.57\%) of dogs infected with Leishmania were also infected with the Toxoplasma. The main reason for this difference in the prevalence of infection with these parasites in the studied dogs is related to the transmission route of the parasite, which is entirely different for Leishmania and Toxoplasma and somewhat different for Neospora. Thus, the frequency of coinfection with these parasites in the studied dogs was low.

There was no significant association between the sex of dogs and prevalence of the Toxoplasma infection in the current study [31,32]. This finding is consistent with the findings of previous studies. According to Dubey and Beattie, T. gondii infection in free-ranging carnivores could be an indirect predictor of parasite infection across the regions [1]. Thus, the relatively high prevalence of Toxoplasma infection in dogs in the current study indicates a high prevalence of infection in other animals as well as the human population in the studied area.

\section{Conclusion}

The results of the present survey show a relatively high prevalence of T. gondii infection among dogs and suggest a need for a larger study on dogs and also a survey of the infection in cats and humans to identify the importance of the dogs in the epidemiology of Toxoplasma infection.

\section{Data Availability}

The datasets generated and analyzed during the current study are available in the table. The quantitative data used to support the findings of this study are available from the corresponding author upon request.

\section{Conflicts of Interest}

The authors declare that they have no conflicts of interest.

\section{Acknowledgments}

This study was undertaken as an MD degree thesis for Ali Zeighami. The study was financially supported by the office of vice-chancellor for research of Shiraz University of Medical Sciences (Grant No. 97-01-01-18951).

\section{References}

[1] J. P. Dubey and C. Beattie, Toxoplasmosis of Animals and Man, CRC Press, Inc., 1988.

[2] A. Tenter, A. Heckeroth, and L. M. Weiss, "Erratum to _Toxoplasma gondii_: from animals to humans Int. J. Parasitol. 30 2000 1217-1258," International Journal for Parasitology, vol. 31, no. 2, pp. 217-220, 2001.

[3] J. Flegr, J. Prandota, M. Sovičková, and Z. H. Israili, “Toxoplasmosis-a global threat. Correlation of latent toxoplasmosis with specific disease burden in a set of 88 countries," PLoS One, vol. 9, no. 3, p. e90203, 2014.

[4] J. D. Kravetz and D. G. Federman, "Toxoplasmosis in pregnancy," Journal of Medicine, vol. 118, no. 3, pp. 212-216, 2005.

[5] E. Bokova, M. Kuptsova, E. Gorozhanina, D. Bogomolov, I. Berechikidze, and A. Grinev, "Peculiarities of interaction in the" parasite-host" system in HIV-infected patients with 
toxoplasmosis: literature and clinical CASE review," Georgian Medical News, vol. 301, pp. 130-136, 2020.

[6] D. Lindsay, J. Dubey, J. Butler, and B. Blagburn, "Mechanical transmission of _Toxoplasma gondii_oocysts by dogs," Parasitology, vol. 73, no. 1-2, pp. 27-33, 1997.

[7] J. P. Dubey, F. H. A. Murata, C. K. Cerqueira-Cézar, O. C. H. Kwok, Y. Yang, and C. Su, "_Toxoplasma gondii_ infections in dogs: 2009-2020," Veterinary Parasitology, vol. 287, no. 287, article 109223, 2020.

[8] J. P. Dubey, J. A. Cortés-Vecino, J. J. Vargas-Duarte et al., "Prevalence of _Toxoplasma gondii_in dogs from Colombia, South America and genetic characterization of _T. gondii_isolates," Veterinary Parasitology, vol. 145, no. 1-2, pp. 45-50, 2007.

[9] P. R. Romanelli, R. L. Freire, O. Vidotto et al., "Prevalence of _Neospora caninum_ and _Toxoplasma gondii_ in sheep and dogs from Guarapuava farms, Paran a State, Brazil," Research in Veterinary Science, vol. 82, no. 2, pp. 202-207, 2007.

[10] G. Duan, Y.-M. Tian, B.-F. Li et al., "Seroprevalence of Toxoplasma gondii infection in pet dogs in Kunming, Southwest China," Parasites \& vectors, vol. 5, no. 1, 2012.

[11] J. P. Dubey, R. P. V. J. Rajapakse, R. R. M. K. K. Wijesundera et al., "Prevalence of _Toxoplasma gondii_ in dogs from Sri Lanka and genetic characterization of the parasite isolates," Veterinary parasitology, vol. 146, no. 3-4, pp. 341-346, 2007.

[12] A. Uggla, S. Mattson, and N. Juntti, "Prevalence of antibodies to Toxoplasma gondii in cats, dogs and horses in Sweden," Acta Veterinaria Scandinavica, vol. 31, no. 2, pp. 219-222, 1990.

[13] A. P. Lopes, H. Santos, F. Neto et al., "Prevalence of antibodies to Toxoplasma gondii in dogs from northeastern Portugal," Journal of Parasitology., vol. 97, no. 3, pp. 418-420, 2011.

[14] A. B. Ayinmode, O. O. Ishola, and T. A. Oderinu, "Seroprevalence of Toxoplasma gondii in dogs slaughtered for food in Southwestern Nigeria and assessment of consumer's knowledge and behavior," Alexandria Journal of Veterinary Sciences, vol. 45, no. 1, p. 161, 2015.

[15] J. Kamani, A. U. Mani, H. A. Kumshe et al., "Serosurvey for Toxoplasma gondii in dogs in Maiduguri, Borno State, Nigeria," The Journal of Infection in Developing Countries, vol. 4, no. 1, pp. 15-18, 2010.

[16] A. M. Johnson, P. Phillips, and D. Jenkins, "Prevalence of Toxoplasma gondii antibodies in dingoes," Journal of wildlife diseases., vol. 26, no. 3, pp. 383-386, 1990.

[17] A. Watson, B. Farrow, and P. McDonald, Prevalence of Toxoplasma Gondii Antibodies in Pet Dogs and Cats, 1982.

[18] G. Desmonts and J. S. Remington, "Direct agglutination test for diagnosis of Toxoplasma infection: method for increasing sensitivity and specificity," Journal of clinical microbiology., vol. 11, no. 6, pp. 562-568, 1980.

[19] A. Paugam, J. Dupouy-Camet, M.-H. Sumuyen, S. Romand, J. Lamoril, and F. Derouin, "Detection of Toxoplasma gondii parasitemia by polymerase chain reaction in perorally infected mice," Parasite, vol. 2, no. 2, pp. 181-184, 1995.

[20] F. Zarra-Nezhad, M. P. Borujeni, B. Mosallanejad, and H. Hamidinejat, "A seroepidemiological survey of Toxoplasma gondiiinfection in referred dogs to Veterinary Hospital of Ahvaz, Iran," International journal of veterinary science and medicine., vol. 5, no. 2, pp. 148-151, 2017.
[21] J. Gharekhani, M. Yakhchali, E. Abbasi-Doulatshahi, and E. Barati, "Seroprevalence ofNeospora caninumandToxoplasma gondiiInfections in stray dogs of Hamadan suburb, West of Iran, 2018," Avicenna Journal of Clinical Microbiology and Infection., vol. 6, no. 2, pp. 57-60, 2019.

[22] J. Gharekhani, A. Gerami-Sadeghian, G. Tavoosidana, and A. Sohrabei, "Seroepidemiology of Toxoplasma gondii infection in dogs and domestic equine from western Iran," Comparative Clinical Pathology., vol. 24, no. 2, pp. 255-258, 2015.

[23] M. Hosseininejad, A. Malmasi, F. Hosseini, M. Selk-Ghaffari, N. Khorrami, and M. Mohebali, "Seroprevalence of Toxoplasma gondii infection in dogs in Tehran, Iran," Iranian journal of parasitology., vol. 6, no. 1, pp. 81-85, 2011.

[24] R. Sharma, S. Parker, B. Al-Adhami, N. Bachand, and E. Jenkins, "Comparison of tissues (heart vs. brain) and serological tests (MAT, ELISA and IFAT) for detection of _Toxoplasma gondii_ in naturally infected wolverines (_Gulo gulo_) from the Yukon, Canada," Parasitology, vol. 15, p. e00046, 2019.

[25] C. Zhu, L. Cui, and L. Zhang, "Comparison of a commercial ELISA with the modified agglutination test for detection of toxoplasma gondii antibodies in sera of naturally infected dogs and cats," Iranian journal of parasitology, vol. 7, no. 3, pp. 8995, 2012.

[26] N. Arefkhah, R. Goodarzi, Z. Rezaei, A. Layegh Gigloo, and B. Sarkari, "Low prevalence of Toxoplasma gondii infection among children in a rural community in Fars province Southern Iran," Le infezioni in medicina., vol. 27, no. 3, pp. 322-327, 2019.

[27] I. J. Blader and J. P. Saeij, "Communication between Toxoplasma gondii and its host: impact on parasite growth, development, immune evasion, and virulence," APMIS, vol. 117, no. 5-6, pp. 458-476, 2009.

[28] I. I. G. G. Taques, T. R. Barbosa, A. de Cássia Martini et al., "Molecular assessment of the transplacental transmission of _Toxoplasma gondii_,_Neospora caninum_,_Brucella canis_ and _Ehrlichia canis_ in dogs," Comparative immunology, microbiology and infectious diseases, vol. 49, pp. 47-50, 2016.

[29] L. Najafi, M. Omidian, Z. Rezaei et al., "Molecular and serological evaluation of zoonotic visceral leishmaniasis in dogs in a rural area of Fars province, southern Iran, as a source of Leishmania infantum infection," Veterinary Medicine and Science, vol. 7, no. 4, pp. 1082-1089, 2021.

[30] M. Hariri, N. Arefkhah, F. Ghorbani, M. Namavari, M. Omidian, and B. Sarkari, "Molecular and serological evaluation of Neospora caninum infection in dogs from a rural setting in Fars Province, Southern Iran," Iranian Journal of Parasitology, vol. 16, no. 1, pp. 146-150, 2021.

[31] K. Yildiz, S. Y. Duru, B. B. Yagci et al., "Seroprevalence of Neospora caninum and coexistence with Toxoplasma gondii in dogs," Türkiye Parazitoloji Dergisi, vol. 33, no. 2, pp. 116119, 2009.

[32] B. Ahmed, S. Gaafar, W. Weirich, and C. Kanitz, "Relationship of toxoplasma infections to other diseases in dogs," Veterinary parasitology, vol. 12, no. 2, pp. 199-203, 1983. 